\title{
Recuerdos de Hungría: la reina Violante de Aragón, Helena de Veszprém y el díptico-relicario de santa Úrsula del monasterio de las Huelgas de Burgos
}

\author{
Memories of Hungary: Queen Violante of Aragón, Helen of Veszprém \\ and the Diptych-Reliquary of St Ursula from the Monastery of las \\ Huelgas in Burgos
}

\author{
Diana LUCÍA GÓMEZ-CHACÓN \\ CSDMM - Universidad Politécnica de Madrid
}

ORCID: http://orcid.org/0000-0002-0197-7185 / dianalucia@upm.es

DOI: http://dx.doi.org/10.18002/da.v0i19.5915

Recibido: 24-II-2020

Aceptado: 7-V-2020

RESUMEN: En la Sala de Labor del monasterio de Santa María la Real de las Huelgas se expone desde 2015 el llamado díptico-relicario de santa Úrsula, fechado en el siglo XIII. Una pieza que, a pesar de su enorme singularidad, carecía de un estudio monográfico. En el presente trabajo se analiza su iconografía y se corrige la identificación de una de las santas representadas. Esta relectura, unida a un análisis formal de la misma, permite aportar nuevos datos acerca del origen de la pieza, precisar su cronología, así como plantear una hipótesis en relación a cómo pudo llegar al monasterio burgalés.

Palabras clave: Monasterio de las Huelgas; Díptico-relicario de santa Úrsula; Queenship; Violante de Aragón; Helena de Veszprém; Dinastía Arpad; Convento de Santa Catalina de Veszprém; Convento de Nuestra Señora de la Isla de las Liebres de Buda.

ABSTRACT: Since 2015 the so-called 13th century diptych-reliquary of Saint Ursula is exhibited in the Labour Hall of the monastery of Las Huelgas in Burgos. Despite its uniqueness, the abovementioned diptych-reliquary lacked a monographic study. The present work analyses its iconography, and corrects the identification of one of the saints represented in it. This rereading, together with a formal analysis, provides new information about the origin of the piece, it offers a more accurate chronology, and proposes a hypothesis in relation to how the diptych reached Las Huelgas.

Keywords: Monastery of Las Huelgas; Diptych-reliquary of St Ursula; Queenship; Violante de Aragón; Helen of Veszprém; Arpad dynasty; Convent of St Catherine in Veszprém; Convent of Our Lady of the Hares' Island in Buda.

\section{INTRODUCCIÓN}

Desde 2015 se expone en la Sala de Labor del monasterio de las Huelgas de Burgos un díptico-relicario ${ }^{1}$, fechado en el siglo XIII,

\footnotetext{
${ }^{1}$ El presente artículo se ha elaborado en el marco
}

del proyecto coordinado “MUNARQAS. Las mujeres de las Monarquías Ibéricas: paradigmas institucionales, agencias políticas y modelos culturales". Subproyecto 1. "Reinas e infantas de las monarquías ibéricas: espacios religiosos, modelos de representación y escrituras, ca. 1252-1504", PGC2018-099205-B-C21, convocatoria 


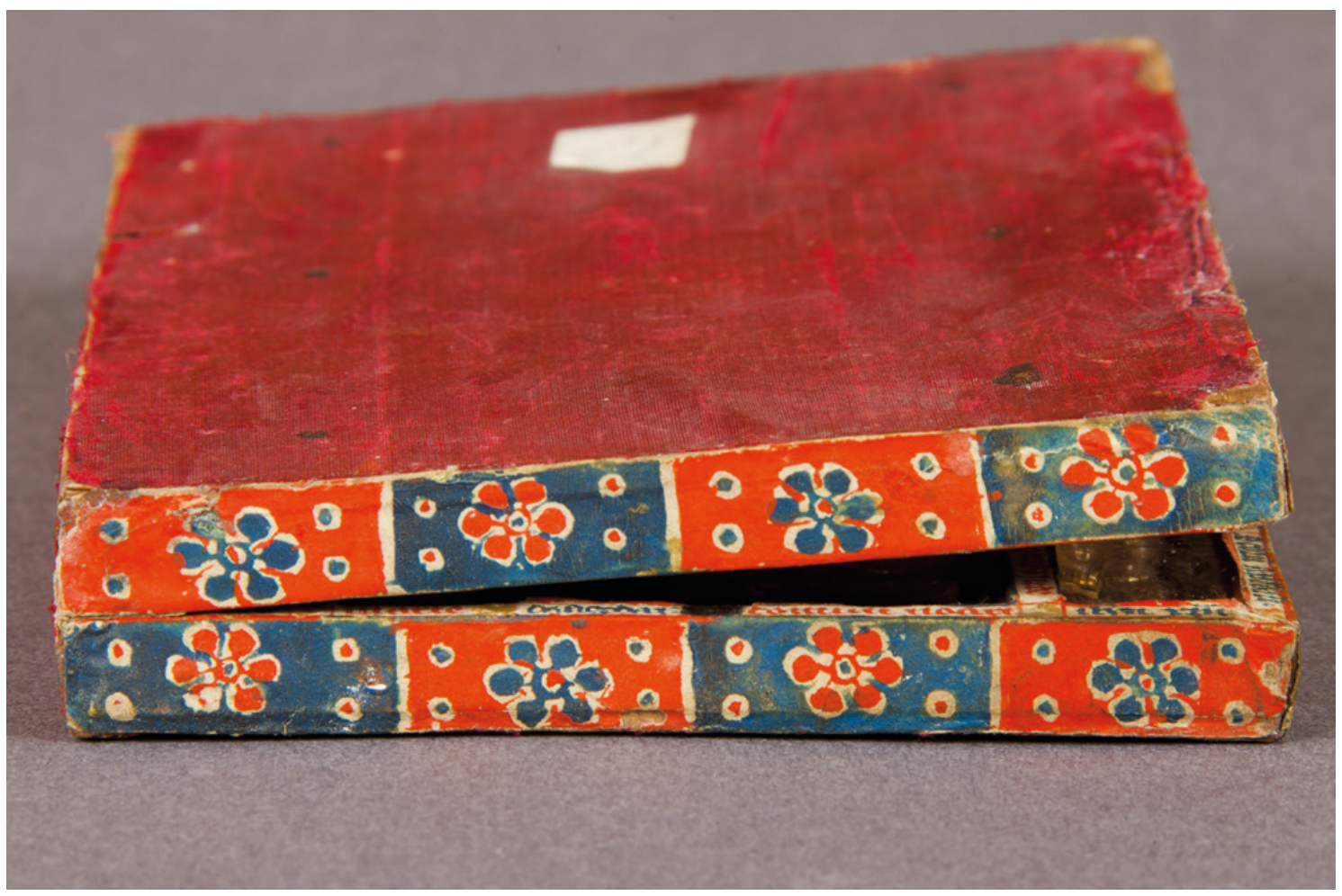

- Fig. 1. Díptico-relicario de santa Úrsula cerrado. Último cuarto del siglo XIII. Alma de madera, papel, plata, espejuelo, pedrería y tela. Patrimonio Nacional, inv. 00650347. Monasterio de Santa María la Real de las Huelgas, Burgos. (C) Patrimonio Nacional.

anteriormente ubicado en el retablo-baldaquino o armario-relicario del coro de las monjas -levantado en el siglo XVI, a causa de la imposición de nuevas normas de clausura-, el cual se encuentra profundamente alterado por las intervenciones que ha sufrido a lo largo de los siglos 2 .

Apenas se conocen datos acerca de esta singular obra que figura, por primera vez, en los inventarios del monasterio de principios del siglo XX. Sin embargo, este dato no indicaría necesariamente que el díptico-relicario

2018 de Proyectos de I+D de Generación de Conocimiento del Subprograma Estatal de Generación de Conocimiento, correspondiente al Programa Estatal de Generación de Conocimiento y Fortalecimiento Científico y Tecnológico del Sistema de I+D+I. Ministerio de Ciencia, Innovación y Universidades.

2 Olga Pérez Monzón, "'Bien contar [supieron] las gestas del buen rey'. Memoria visual de Alfonso VIII", en Alfonso VIII y Leonor de Inglaterra: confluencias artísticas en el entorno de 1200, ed. por Marta Poza Yagüe y Diana Olivares Martínez (Madrid: Ediciones Complutenses, 2017), 131-132. hubiese llegado al monasterio entonces. A pesar de la existencia de inventarios anteriores, fechados en el siglo XIX, en estos no se hace alusión a las reliquias custodiadas en el cenobio, lo que justificaría la ausencia de referencias a la pieza objeto de estudio.

Por otro lado, si bien sabemos que el monasterio de las Huelgas recibió a lo largo de la segunda mitad del siglo XIX diversos objetos para el culto procedentes de cenobios filiales, lo cierto es que determinados detalles, los cuales serán expuestos a lo largo de este trabajo, hacen sospechar que el origen de esta pieza pudo haber sido otro muy distinto, pudiendo haber llegado el relicario al monasterio burgalés a finales del siglo XIII, de manos de Violante de Aragón, reina de Castilla (1252-1284).

\section{DESCRIPCIÓN Y ANÁLISIS DE LA PIEZA}

El díptico-relicario está formado por dos paneles de madera, forrados de seda roja, 


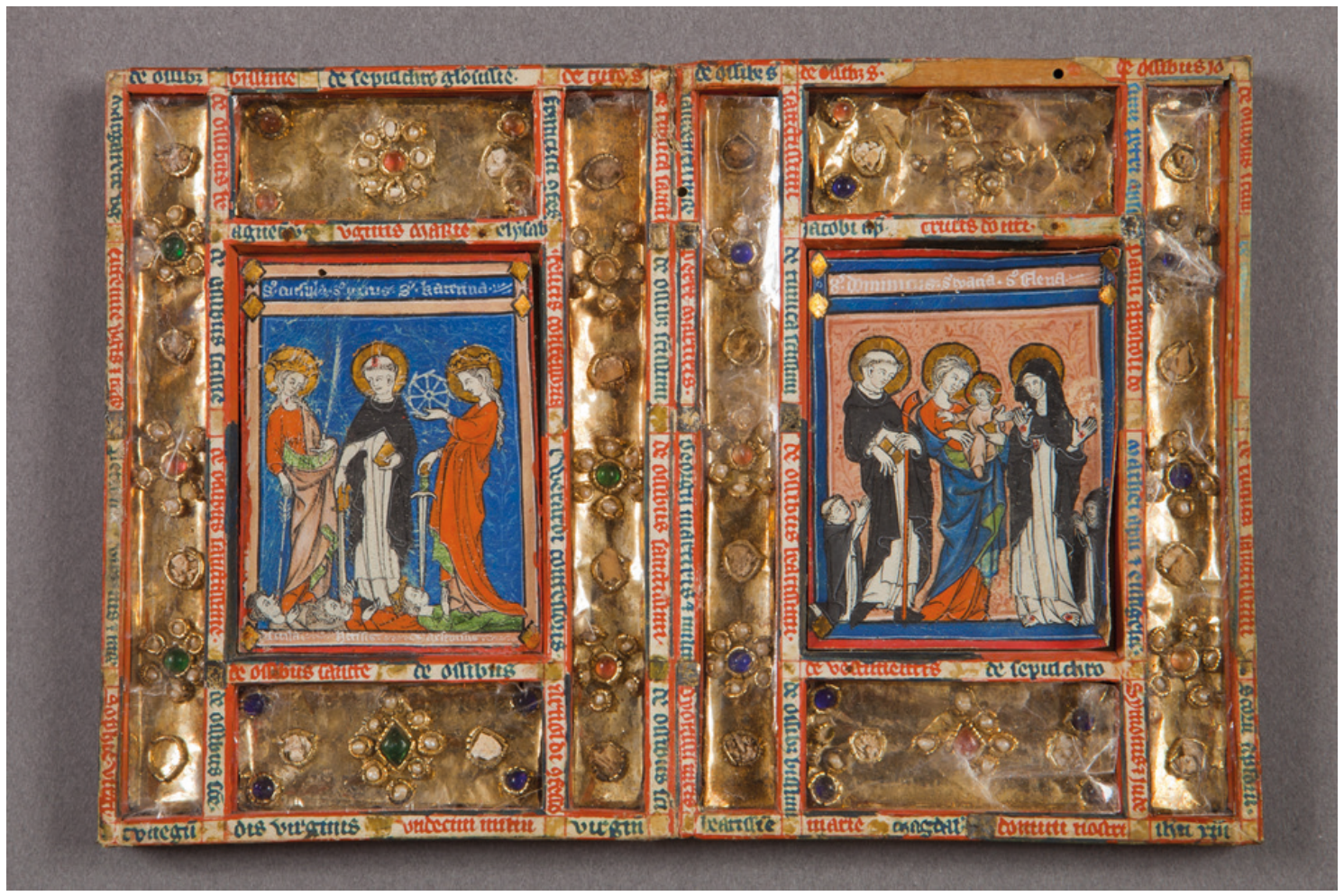

- Fig. 2. Imagen del díptico-relicario de santa Úrsula abierto. Último cuarto del siglo XIII. Alma de madera, papel, plata, espejuelo, pedrería y tela. Patrimonio Nacional, inv. 00650347. Monasterio de Santa María la Real de las Huelgas, Burgos. (C) Patrimonio Nacional.

donde se insertan dos miniaturas, rodeadas por cuatro espacios acristalados, a modo de viriles, con el interior forrado por una lámina de plata dorada con piedras de colores y pequeñas perlas o aljófares. El ancho de ambas hojas está decorado con flores de seis pétalos (Fig. 1). Inscripciones en latín, en rojo y azul sobre fondo blanco, identifican las diversas reliquias atesoradas, pertenecientes a la Virgen, santa Isabel, santas vírgenes y mártires (santa Inés, santa Margarita, santa Eufemia, ¿santa Petronila? ${ }^{3}$ y santa Sofía) y santos confesores (san Francisco, ¿san Zoerardo ${ }^{4}$, san Félix y san Arnaldo) en la valva izquierda y apóstoles (Pedro, Pablo, Mateo,

\footnotetext{
${ }^{3}$ El fragmentario estado de conservación del texto impide asegurar que se trate de la mencionada santa. Por este mismo motivo, no se incluye en el presente trabajo una transcripción detallada de los epígrafes, cuya correcta lectura requiere de un estudio pormenorizado desde el ámbito paleográfico, que no tiene cabida en el contexto de este artículo.
}

${ }^{4}$ La lectura del nombre de este santo presenta algunas dudas.
Simón, Judas y Santiago), ¿san Martín?5, santos mártires (san Lorenzo, san Pedro Mártir de Verona, san Jorge y san Dionisio), María Magdalena, santos y beatos sin concretar y reliquias pasionales (túnica y vestimentas de Cristo, Cruz y sepulcro), en la valva derecha (Fig. 2). En 2017 el díptico-relicario fue sometido a una restauración. Se llevó a cabo una limpieza en profundidad y se consolidaron las partes sueltas o desprendidas. Además, se analizaron tanto los hilos de plata y cobre dorados, como los viriles, fabricados en lapis specularis o espejuelo.

Si bien Cristina de Benedictis sitúa el origen de los relicarios vidriados en Asís, ninguno de los doce ejemplos estudiados por la mencionada autora procedería de dicha ciudad y tan solo cinco de estos, entre los

\footnotetext{
${ }^{5}$ La lectura del nombre de este santo tampoco resulta clara.

${ }^{6}$ Agradezco a María Jesús Herrero Sanz que me facilitase los datos relativos a la restauración de la pieza.
} 
que no se incluye el que nos ocupa, estarían ligados a la orden franciscana. Entre las piezas estudiadas por De Benedictis destacan por su semejanza estructural con el díptico de Santa Úrsula, los dípticos-relicarios de Santa Clara de Asís, la Walters Art Gallery (N. Inv. 46.2), el Museo del Bargello (N. Inv. 45v), la colegiata de Santa María Assunta de Fumone (Frosinone), Santa María di Castello de Génova, la National Gallery of Victoria de Melbourne (N. Inv. C. 2484.1910), The Metropolitan Museum of Art de Nueva York (N. Inv. 17.190.922 y 17.190.982), el Museo del Duomo de Recanati, el Museo Diocesano de Spoleto y el Museo Diocesano di Arte Sacra de Volterra. Los ejemplos documentados por De Benedictis datan de entre 1310 y 1350, habiendo excluido de su trabajo los ejemplos localizados por la autora fechados a principios del siglo XV. A pesar de ello no se debe descartar la posible existencia de piezas similares realizadas tanto en fechas anteriores como posteriores a las analizadas por De Benedictis. De hecho, la propia autora menciona objetos similares a los dípticos-relicarios, como, por ejemplo, los tabernáculos-relicarios, entre los que destaca el de Castiglion Fiorentino, procedente de la iglesia de San Francisco, que data de hacia $1290^{7}$.

El díptico-relicario de las Huelgas presenta una iconografía de clara devoción dominicana, lo que, en principio, descartaría el hecho de que hubiese sido encargado ex profeso por o para algún miembro de la comunidad de religiosas del monasterio burgalés, pudiendo tratarse, por lo tanto, de una donación realizada a este. En la hoja o valva izquierda aparecen representados de pie santa Úrsula -quien sujeta en su mano derecha la flecha con la que fue atravesado su corazón, la palma del martirio en la izquierda y la figura del rey Atila bajo sus pies-, san Pedro Mártir - protomártir de la Orden de Predicadores, muestra una herida en la cabeza, aparentemente otra en el pecho, una espada en

\footnotetext{
7 Cristina de Benedictis, Devozione e produzione artística in Umbria. Vetri dorati e graffiti del XIV e XV secolo (Florencia: Edifir-Edizioni Firenze, 2010), 15.
}

su mano derecha y un hereje a sus pies- y santa Catalina de Alejandría -con la rueda dentada en la mano izquierda, la espada en la derecha y el rey Majencio bajo sus pies-. Este último, al igual que las otras dos figuras sometidas, conserva una inscripción identificativa en latín (Fig. 3).

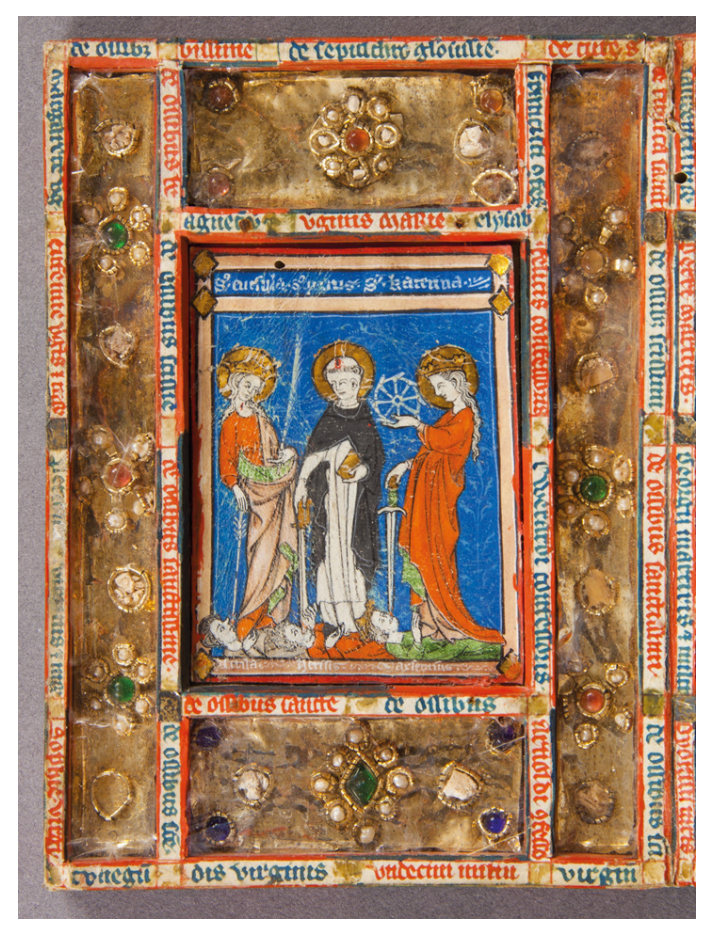

- Fig. 3. Hoja izquierda del díptico-relicario de santa Úrsula. Último cuarto del siglo XIII. Alma de madera, papel, plata, espejuelo, pedrería y tela. Patrimonio Nacional, inv. 00650347. Monasterio de Santa María la Real de las Huelgas, Burgos. (C) Patrimonio Nacional.

En la hoja derecha aparecen santo Domingo de Guzmán -que porta un libro y un báculo, objetos que habría recibido de manos de san Pedro y san Pablo-, la Virgen con el Niño y, por último, una figura femenina sobre la cual se lee "S. Elena" que ha sido identificada como santa Helena, madre del emperador Constantino, que aparecería mostrando los estigmas en alusión al descubrimiento de la Vera Cruz. Junto a santo Domingo de Guzmán y "S. Elena” aparecen, además, dos figuras arrodilladas, en actitud orante, que visten hábito dominicano y que habría que identificar, respectivamente, como un fraile y una monja, miembros anó- 
nimos de la Orden de Predicadores, carentes de nimbo (Fig. 4).

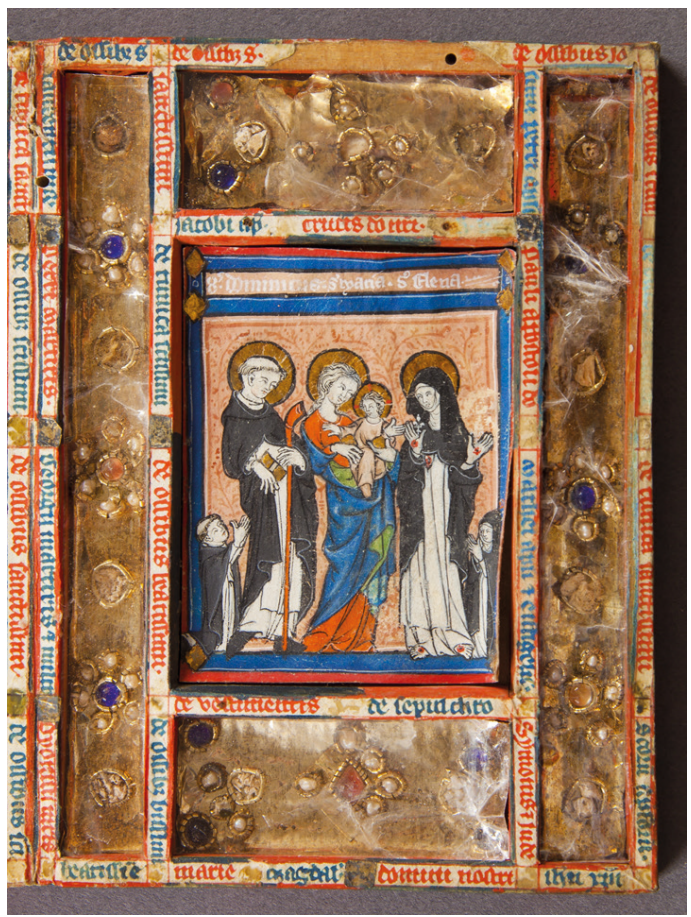

- Fig. 4. Hoja derecha del díptico-relicario de santa Úrsula. Último cuarto del siglo XIII. Alma de madera, papel, plata, espejuelo, pedrería y tela. Patrimonio Nacional, inv. 00650347. Monasterio de Santa María la Real de las Huelgas, Burgos. (C) Patrimonio Nacional.

La identificación iconográfica de los santos representados resulta sencilla, a excepción de la última figura. Si nos fijamos, no solo muestra estigmas en pies y manos, sino que, además, de la llaga de la mano derecha brota un motivo floral blanco, con forma de flor de lis. La presencia de los estigmas y la flor blanca, sumados al atuendo que luce la santa -túnica blanca, y manto y velo negros, es decir, el hábito de la rama femenina de la Orden de Predicadores y, por consiguiente, el mismo que viste la religiosa arrodillada junto a ella-, descartarían por completo la identificación de la mencionada figura femenina como santa Helena, madre de Constantino, si bien la inscripción colocada sobre la figura la identifica claramente como "S. Elena" (Fig. 5).

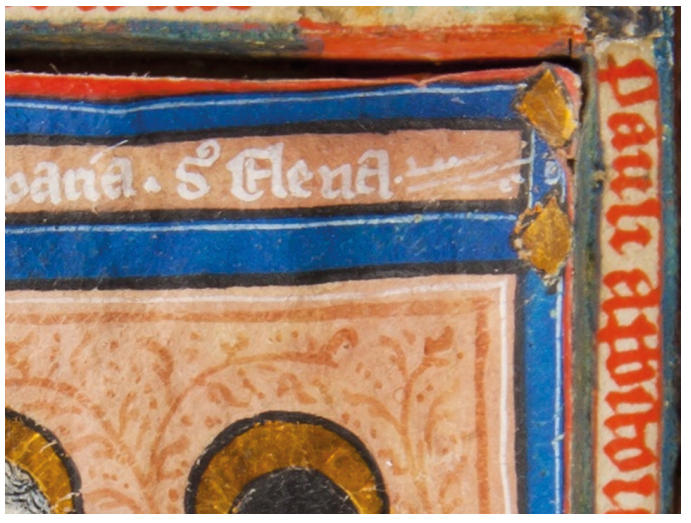

- Fig. 5. Detalle de la inscripción de "S. Elena". Último cuarto del siglo XIII. Alma de madera, papel, plata, espejuelo, pedrería y tela. Patrimonio Nacional, inv. 00650347. Monasterio de Santa María la Real de las Huelgas, Burgos. (C) Patrimonio Nacional.

\section{IN CICATRICE MANUS DEXTRAE CREVIT FILUM AUREUM}

En la sacristía de Santa María Novella se conserva una tabla de hacia 1350 decorada con la imagen de una santa dominicana coronada, que porta un lirio en una mano, mientras que, en la otra, con la que sostiene un orbe, se aprecia claramente un estigma. Se trata de santa Margarita de Hungría, fallecida el 18 de enero de $1270^{8}$. El proceso de canonización de la mencionada religiosa contó desde sus inicios, en 1273, con el apoyo no solo de la propia Orden de Predicadores, sino también con el de su hermano, el rey Esteban V de Hungría (1270-1272). En época medieval se documentan, al menos, tres intentos de canonización de la religiosa húngara promovidos por la casa real angevina (1306, 1340 y 1379). Fue precisamente a consecuencia del deseo de impulsar y propagar el culto a Margarita de Hungría por tierras italianas, que se difundió la leyenda de que la religiosa había lucido estigmas en su cuerpo ${ }^{9}$.

8 Gábor Klaniczay, "Pouvoir et idéologie dans l'hagiographie des saintes reines et princesses", en $\mathrm{Ha}$ giographie, idéologie et politique au Moyen Âge en Occident, ed. por Edina Bozóky (Turnhout: Brepols, 2012), 435.

\footnotetext{
${ }^{9}$ Gábor Klaniczay, "Efforts at the Canonization of Margaret of Hungary in the Angevin Period", Hungarian Historical Review, no 2 (2013), 316-319.
} 
Hacia 1417-1418 Tommaso d'Antonio Caffarini (†1434) redactó su Libellus de Supplemento, obra que habría de completar la información contenida en la legenda maior de santa Catalina de Siena. En un intento de defender la naturaleza luminosa de los estigmas de la santa terciaria, Caffarini trató de demostrar la existencia de una relativamente amplia variedad de estigmatizaciones, temática que desarrolla en su extenso Tractatus de stigmatibus, fechado hacia 1412 e inserto en el capítulo VII del Libellus. Para ello recuperó no solo la historia de san Francisco de Asís, sino también las vidas de otros santos y beatos que habían sido igualmente premiados con los estigmas ${ }^{10}$.

Con el deseo de documentarse acerca de la estigmatización de santa Margarita de Hungría, en 1409 Caffarini escribió al prior provincial húngaro, fray Gregorio, el cual le indicó que no fue santa Margarita de Hungría quien recibió los estigmas de Cristo, sino su magistra, la beata Helena, información que hizo que Caffarini mandase retirar la representación de Margarita de Hungría conservada en su convento de Venecia. El prior húngaro, aprovechando la oportunidad que le ofrecía la consulta realizada por Caffarini, le envió la legenda más antigua conservada de Margarita, escrita hacia 1275, junto con la de Helena de Hungría o de Veszprém, redactada entre 1241 y 1272. Ambas obras fueron copiadas en el convento veneciano, experimentando una mayor difusión a finales del siglo XV, de manos de Girolamo Borselli y Ambrogio Taeggio, cronistas de la Orden de Predicadores, y siendo recuperadas ya en pleno siglo XX desde el campo de la filología ${ }^{11}$.

${ }^{10}$ Gábor Klaniczay, “Le stigmata di santa Margherita d'Ungheria: immagini e testi", Iconographica. Rivista di iconografía medievale e moderna", I (2002), 16; Gábor Klaniczay, "On the Stigmatization of Saint Margaret of Hungary", en Medieval Christianity in Practice, ed. por Miri Rubin (Princeton: Princeton University Press, 2009), 276.

${ }^{11}$ Robert Fawtier, “La vie de la Bienheureuse Hélène de Hongrie", Mélanges d'archéologie et d'histoire, Tomo 33 (1913), 11; Klaniczay, “Le stigmata di santa Margherita
Dos de las copias del Libellus de Supplemento (Siena, Biblioteca comunale degli Intronati T.I.2 y Bolonia, Biblioteca universitaria 1574), realizadas ambas en el scriptorium del convento de San Juan y San Pablo de Venecia, contienen representaciones de las estigmatizaciones tanto del dominico Walter de Strasburgo (†1264) como de Helena de Hungría (†1285), imágenes que Caffarini habría mandado incluir bajo su atenta supervisión puesto que aseguraba haber visto, a pesar de la existencia de testimonios escritos de las distintas estigmatizaciones, algunas imágenes que contenían errores iconográficos. Errores que aspiraba a solventar con su aportación $^{12}$.

Según una de las copias conservadas de su legenda fechada a principios del siglo XV, sor Helena habría recibido los estigmas en manos, pies y costado en 1237. La primera llaga habría aparecido en la mano derecha, en la noche anterior a la festividad de san Francisco de Asís, y la segunda el día de los santos Pedro y Pablo, al mediodía. De la llaga de la mano derecha habría brotado un lirio, al que aludiría el anteriormente mencionado motivo floral que nace precisamente de la llaga de la mano derecha de la "S. Elena" del díptico-relicario objeto de estudio: In cicatrice manus dextrae crevit filum aureum et crines et filum aurem cum tortura extendebatur in longum, motivo que, en ocasiones, a causa de una contaminación iconográfica, luce santa Margarita de Hungría. Según algunas versiones de su legenda, al poco tiempo comenzarían a crecer lirios del resto de estigmas.

d'Ungheria...", 18 y 25; Gábor Klaniczay, Holy Rulers and Blessed Princesses: Dynastic Cults in Medieval Central Europe (Cambridge: Cambridge University Press, 2002), 378 y 383; Gábor Klaniczay, "Estasi e stigmatizzazione: il miracolo vissuto e presentato", en Miracolo! Emozione, spettacolo e potere nella sotira dei secoli XIII-XVII, ed. por Laura Andreani y Agostino Paravicini Bagliani (Florencia: SISMEL, Edizioni del Galuzzo, 2019), 167.

${ }^{12}$ Carolyn Muessig, "The Stigmatic Debate in Theology and Art in the Late Middle Ages", en The Authority of the Word. Reflecting on Image and Text in Northern Europe, 1400-1700, ed. por Celeste Brusati, Karl A. E. Enenkel y Walter S. Melion (Leiden: Brill, 2012), 490. 
Estos eran cortados y recolectados por el resto de religiosas del convento de Veszprém ${ }^{13}$.

Las primeras versiones de la vita de Helena de Hungría habrían sido redactadas entre 1241 y 1272 por las propias religiosas del convento de Santa Catalina de Veszprém. Si bien en las actas del proceso de canonización de Margarita de Hungría no se menciona el nombre de Helena de Hungría o de Veszprém, también es cierto que en ningún momento se interroga a los testigos en relación a los maestros que pudo haber tenido la religiosa durante su infancia. En su Quodlibet (1310-1330) el franciscano Petrus Thomae hace alusión, con motivo de la controversia en torno a la figura de san Francisco de Asís, a una domina Helena, ut dicitur, habuit Stigmata etiam cum [lacuna], ut a quibusdam trufatoribus depingitur, que vuelve a ser mencionada en la legenda de santa Margarita de Hungría de Pierre Razan, escrita hacia $1490^{14}$.

El culto a la mencionada religiosa, de escasa proyección, se habría comenzado a difundir por tierras húngaras en una fecha próxima, quizás, no tanto a su fallecimiento, como a la redacción por parte de la comunidad de Santa Catalina de Veszprém de la legenda de la religiosa. La inclusión de la imagen de Helena de Veszprém sumada al hecho de que se la denomine "S. Elena", a pesar de no haber sido canonizada, hacen pensar que el relicario burgalés es una pieza procedente de Hungría, y, más concretamente, de alguno de los conventos a los que estuvo ligada la memoria de la religiosa, en los que se le habría rendido culto, como lo fueron, o bien el mencionado convento de Santa Catalina de Veszprém, o bien el de Nuestra Señora de la Isla de las Liebres de Buda.

\footnotetext{
${ }^{13}$ Fawtier, "La vie de la Bienheureuse...", 10 y 15; Klaniczay, "Le stigmata di santa Margherita d'Ungheria...", 23; Klaniczay, "On the Stigmatization...", 276 y 281-282.
}

${ }^{14}$ Alexis Léonas, Les Petites Fleurs de sainte Marguerite de Hongrie (París: Les Éditions du Cerf, 2013), 21.
HELENA DE VESZPRÉM Y LA DINASTÍA ARPAD

El convento de dominicas de la Isla Margarita, conocida como la Isla de las Liebres (Insula Leporum) en época medieval, en Buda, fue construido entre 1246 y 1253 por orden de Bela IV (1235-1270), rey de la dinastía Arpad, extinta en 1301, y su mujer, Maria Laskaris, para su hija Margarita (1242-1270) y más de setenta religiosas pertenecientes a la élite aristocrática húngara ${ }^{15}$. La fundación del convento habría sido fruto de una promesa del rey Bela IV. Durante su exilio, el monarca prometió entregar a Dios el hijo que esperaba si lograba recuperar sus territorios de manos de los tártaros, quienes ocuparon Hungría entre 1241 y 1242. Una vez de vuelta en su reino, la princesa Margarita fue consagrada a la vida religiosa. Con tan solo cuatro años ingresó en el convento de Santa Catalina de Veszprém -ciudad integrada en el itinerario habitual de la corte húngara-, fundado hacia 1230. Si bien en un primer momento parece haber sido habitado por un grupo de beguinas, años más tarde pasó a ser administrado por la Orden de Predicadores $^{16}$.

15 Gábor Klaniczay, "Saint Margaret: Royal and Female Sanctity", en Legenda Vetus, Acta Processus Canonizationis et Miracula Sanctae Margaritae de Hungria, ed. por Ildikó Csepregi, Gábor Klaniczay y Bence Péterfi (Budapest-Nueva York: Central European University Press, 2018), 9-10 y 12; José Enrique Salcedo Mendoza, Historia y Arte en la Hungría medieval (Granada: PortRoyal Ediciones, 2014), 211-238 y 265.

${ }^{16}$ Nora Berend, At the Gate of Christendom. Jews, Muslims and 'Pagans' in Medieval Hungary, c. 1000-c. 1300 (Cambridge: Cambridge University Press, 2001), 34-38; Dušan Zupka, Ritual and Symbolic Communication in Medieval Hungary under the Árpád Dynasty (1000-1301) (Leiden-Boston: Brill, 2016), 117; Viktória Hedvig Deák, "Beguines in Hungary? The Case of St Margareta of Hungary (1242-71): A Mystic Without a Voice", en Mulieres religiosae: Shaping Spiritual Authority in the Medieval and Early Modern Periods, ed. por Veerle Fraeters e Imke de Gier (Turnhout: Brepols, 2014), 89-91; Dávid Falvay, "Memory and Hagiography: The Formation of the Memory of Three Thirteenth-Century Female Saints", en The Making of Memory in the Middle Ages, ed. por Lucie Doležalová (Leiden-Boston: Brill, 2010), 350. 
La entrega de su hija a la Orden de Predicadores pudo haber estado motivada asimismo por la especial devoción que tanto el monarca como su esposa sintieron por las órdenes mendicantes, a las que pertenecieron algunos de sus principales consejeros y confesores. Se ha apuntado también la posibilidad de que Helena de Veszprém hubiese abandonado Hungría durante la invasión mongola en compañía de la familia real y que hubiese sido ella misma la encargada de convencer a los reyes para que entregasen a su hija a la Orden de Santo Domingo. Esto explicaría que la princesa fuese finalmente confiada al convento de Santa Catalina de Veszprém y que fuese puesta bajo la protección de la mencionada religiosa ${ }^{17}$.

Años más tarde, Bela IV, movido posiblemente por el deseo de ofrecer a su hija un entorno más propio de su condición regia, habría mandado edificar el mencionado convento en la Isla de las Liebres, sobre un palacio propiedad de la reina, que entregó a la Orden de Predicadores. Transcurrido un año desde la finalización de las obras, en 1254, la princesa Margarita de Hungría profesó como monja dominica, y en 1259 se estableció una pequeña comunidad de frailes dominicos junto al convento, en calidad de capellanes. La directa relación de este convento con la figura de santa Margarita de Hungría hace de él otro posible centro promotor y difusor del culto a Helena de Veszprém, pudiendo haber sido este impulsado por la propia familia real ${ }^{18}$.

Si recordamos las imágenes que decoran el díptico-relicario, la presencia de san Pedro Mártir y santo Domingo de Guzmán estaría plenamente justificada en el caso de que

\footnotetext{
17 Klaniczay, "Saint Margaret...", 8-9.

18 Gábor Klaniczay, "Sacred Sites in Medieval Buda", en Medieval Buda in Context, ed. por Balázs Nagy et al. (Leiden-Boston: Brill, 2016), 236-240; András Végh, "Buda-Pest 1300 - Buda-Pest 1400. Two Topographical Snapshots", en Medieval Buda in Context, 186 y 191; Beatriz F. Romhányi, "The Monastic Topography of Medieval Buda", en Medieval Buda in Context, 204, 207, 210 y 225.
}

este procediese de uno de los dos conventos mencionados. Ambos santos flanquean la imagen de la Virgen con el Niño, cuya inclusión respondería a la profunda devoción mariana de la Orden de Predicadores. Además, debemos recordar que el convento de Buda estaba puesto bajo la advocación de Nuestra Señora. Por otro lado, la presencia de los dos donantes, en especial de la monja dominica, incidiría en la posibilidad de que la pieza objeto de estudio proceda de un cenobio femenino. Al no estar identificados es imposible saber a quiénes representan, pero cabría pensar que se trata de la superiora del convento femenino y del prior de esta, principal responsable de la cura monialium de las religiosas.

La presencia de santa Catalina estaría plenamente justificada por la posible procedencia del díptico del convento de dominicas de Veszprém, puesto bajo la advocación de dicha santa, si bien su culto es también habitual en los cenobios dominicanos femeninos, independientemente de la advocación de estos. En lo que respecta a santa Úrsula de Colonia, la cual, al aparecer representada en primer lugar, en la valva izquierda del díptico, ha dado nombre al mismo, fue objeto de especial culto en Hungría, donde se defendía la relación entre los hunos y los húngaros. Algunas de las versiones conservadas de la vida de la santa hacen de esta una princesa, hija de los reyes de Hungría. Durante el gobierno de la dinastía Arpad (1000-1301), la llegada de población germánica a Hungría habría favorecido el establecimiento del culto a la santa en este reino, lo que habría llevado a incluir su festividad en el calendario húngaro. Franciscanos, dominicos y cistercienses desempeñaron un papel fundamental en la difusión del culto a la santa, cuyas representaciones más antiguas documentadas se remontan a la segunda mitad del siglo XIII ${ }^{19}$.

${ }^{19}$ Anna Tüskés, "The Cult of Ursula in Hungary: Legend, Altars and Reliquaries", en The Cult of St Ursula and the 11,000 Virgins, ed. por Jane Cartwright (Cardiff: University of Wales Press, 2016), 187; Jaime Ferreiro Alemparte, La leyenda de las once mil vírgenes. 


\section{DATACIÓN DE LA PIEZA}

Recordemos que Bela IV era hermano de Violante de Hungría (ca. 1215-1251), segunda esposa de Jaime I de Aragón, el Conquistador (1213-1276), con quien contrajo matrimonio en Barcelona el 8 de septiembre de 1235 , acompañada de un séquito de más de cien personas, entre las que se encontraba Jacometa de Hungría. Esta falleció el 22 de junio de 1258, siendo enterrada en el monasterio de las Huelgas, en la capilla de San Juan Bautista, en el primer arco del lado del Evangelio, según indica su epitafio. Los restos de sus padres, doña Eva y don Jacomet, fueron trasladados a la capilla de San Juan Bautista del monasterio de las Huelgas de Burgos desde Valencia, por deseos de su nieto el maestre Jofré de Loaysa en 1288, con la capilla ya concluida ${ }^{20}$.

Podríamos pensar que Jacometa habría sido la encargada de traer consigo desde Hungría el díptico-relicario y que, una vez en Castilla, lo habría donado al monasterio en el que habría de ser enterrada. Sin embargo, el hecho de que esta abandonase Hungría en 1235 y que falleciese en 1258 descartan esta hipótesis. Resulta imposible que en fechas tan tempranas un objeto de devoción, como es la pieza que nos ocupa, hubiese sido decorado con la efigie de la religiosa dominica, puesto que, como se ha comentado anteriormente, la redacción de la legenda de Helena de Veszprém no se concluyó hasta 1272, año que cabría fijar como fecha post quem para la ejecución del díptico-relicario, en el que, recordemos, se la denomina santa. También se podría llegar a apuntar a la reina como

Sus reliquias, culto e iconografía (Murcia: Universidad de Murcia, 1991), 82, 188-189 y 192.

${ }^{20}$ Alejandro García Morilla, "Las inscripciones medievales de la provincia de Burgos: siglos VIII-XIII" (tesis doctoral, Madrid, 2013), 444-445; Eduardo Carrero Santamaría, “Observaciones sobre la topografía sacra y cementerial de Santa María la Real de Las Huelgas, en Burgos, y su materialización arquitectónica", en $L a$ clausura femenina en España, coord. por Francisco Javier Campos y Fernández de Sevilla (San Lorenzo de El Escorial: Real Centro Universitario Escorial-María Cristina, 2004), vol. 2, 713-714. la responsable de haber entregado la pieza a Jacometa, a modo de regalo. Sin embargo, esto tampoco habría sido posible puesto que Violante de Hungría falleció en 1251. Por lo tanto, quedarían descartadas tanto Jacometa como Violante de Hungría como responsables de la llegada de la pieza objeto de estudio a Castilla, y concretamente al monasterio de las Huelgas, puesto que ambas fallecieron varias décadas antes de que la pieza pudiese haber sido elaborada ${ }^{21}$.

María Jesús Herrero Sanz ha relacionado las dos miniaturas que decoran el díptico-relicario con el scriptorium de Alfonso $X$ el Sabio (1252-1284), hipótesis sobre la que volveremos más adelante ${ }^{22}$. Especialmente llamativos resultan los fondos de ambas imágenes, decorados con un entramado vegetal, solución que encontramos también empleada de manera muy similar en el manuscrito Additional 54180 de la British Library, que contiene una copia iluminada de La Somme le Roy fechada hacia 1295, atribuida al maestro Honoré, que habría pertenecido a Felipe IV, rey de Francia (1285-1314) y Navarra (1284-1305), hijo de Felipe III de Francia (1270-1285) e Isabel de Aragón y, por lo tanto, sobrino de Blanca de Francia, viuda de Fernando de la Cerda, y nieto de Violante de Hungría ${ }^{23}$.

${ }^{21}$ Tampoco pudieron haber traído consigo el díptico los padres de Jacometa ya que, como indica Abella Villar, los trajo consigo de Hungría la reina Violante: Pablo Abella Villar, "Patronazgo regio castellano y vida monástica femenina: morfogénesis arquitectónica y organización funcional del monasterio cisterciense de Santa María La Real de Las Huelgas de Burgos (ca. 1187-1350)" (tesis doctoral, Gerona, 2015), vol. I, 1231.

${ }^{22}$ Agradezco a María Jesús Herrero Sanz que me facilitase el texto que en estos momentos recoge la cartela de la pieza, cuya autoría le corresponde y en el que plantea la hipótesis aquí recogida.

23 Eric G. Millar, The Parisian miniaturist Honoré (Londres: Faber and Faber, 1959), 5-15; François Avril, L'enluminure à l'époque gothique, 1200-1420 (París: Bibliotheque de l'image, 1979), 22-23; Lucy F. Sandler, Gothic Manuscripts, 1285-1385 (Londres: Harvey Miller, 1986), vol. I, 17 y vol. II, 69; L'art au temps des rois maudits: Philippe le Bel et ses fils (1285-1328) (París: Réunion des Musées Nationaux, 1998), 276-277. 
En el díptico-relicario, las dos santas representadas lucen coronas de florones. Estas muestran tres remates trifoliados, estando el central flanqueado por dos formas apuntadas, las cuales se aprecian más claramente en la figura de santa Catalina de Alejandría. Esta misma tipología de coronas es la que aparece en la mencionada copia de $L a$ Somme le Roy de Felipe IV de Francia. Si bien la indumentaria que lucen tanto san Pedro Mártir, como santo Domingo de Guzmán y Helena de Veszprém resulta complicada de fechar al tratarse de hábitos con un marcado carácter atemporal, más sencillo resulta en el caso de santa Úrsula, santa Catalina y la Virgen. Estas visten una túnica de cuello redondo, apenas escotado, ceñida a la cintura, la cual cubren, a su vez, con un amplio manto. Mangas y cuerpo parecen cortados de una sola pieza, técnica de confección propia del siglo XIII, que desdibujaba los pechos y arrugaba ligeramente las sisas ${ }^{24}$.

El rostro, cuello y manos de las figuras que decoran el díptico-relicario apenas muestran coloración, careciendo prácticamente de carnación alguna, al haber optado por un tono blanquecino bastante uniforme, que, por otro lado, permite destacar los perfiles y contornos negros. En lo que respecta al cabello, los mechones son representados cuidadosamente, con un ligerísimo sombreado. La frente queda despejada, retirándose el cabello hacia atrás con formas onduladas que enmarcan el rostro y que se amplían a la altura de las orejas, dejando estas al descubierto, sobre todo en el caso de las dos santas y la Virgen, quienes no llevan velo. Una vez más, hallamos claras semejanzas en el Add. 54180, como, por ejemplo, en la representación del Jardín de las Virtudes (fol. 69v). Asimismo, las dos santas del díptico relicario, santa Úrsula y santa Catalina de Alejandría, aparecen representadas sobre las figuras de Atila y Majencio, respectivamente, composición que recuerda a las imágenes alegóricas

\footnotetext{
${ }^{24}$ Carmen Bernis, “La moda y las imágenes góticas de la Virgen. Claves para su fechación", Archivo Español de Arte, XLIII, no 170 (1970), 195.
}

que decoran los folios 91v, 97v, 107r, 121v, 136v y 188v del Add. 54180 (Fig. 6).

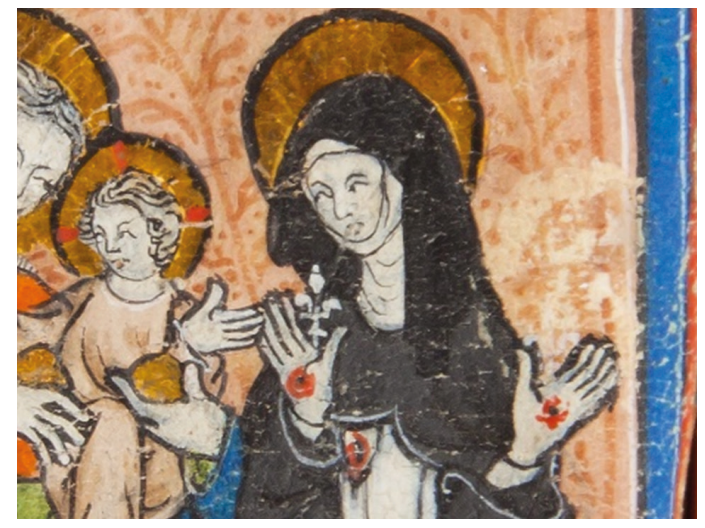

- Fig. 6. Detalle del lirio que brota de la mano derecha de Elena de Veszprém. Último cuarto del siglo XIII. Alma de madera, papel, plata, espejuelo, pedrería y tela. Patrimonio Nacional, inv. 00650347. Monasterio de Santa María la Real de las Huelgas, Burgos. (C) Patrimonio Nacional.

En lo que respecta a las aparentes filiaciones francesas de la pieza objeto de estudio, cabe señalar la existencia de un salterio fechado entre 1242 y 1271 conservado en Alemania, en la Herzog August Bibliothek de Wolfenbüttel (Wolfenbüttel, HAB, Cod. Guelf. Helmst. 52). Se trata de una obra realizada por un taller germánico (sajón-turingio) que copia modelos franceses. El estudio desde el punto de vista litúrgico del manuscrito ha permitido a Anna Boreczky señalar su posible pertenencia a una monja del convento dominico de la Isla de las Liebres $^{25}$. Ante la ausencia de más datos, resulta imposible afirmar que el díptico-relicario de las Huelgas, o, al menos, sus miniaturas, pudiesen haber sido realizadas por el mismo taller o en un ambiente artístico similar. Sin embargo, sí que resulta interesante que, en la pieza que nos ocupa, se repitan la filiación francesa desde el punto de vista formal y la posibilidad de que se trate de un encargo realizado, en origen, por una de las monjas del convento de Nuestra Señora de la Isla de las Liebres de Buda, muy probablemente la

\footnotetext{
${ }^{25}$ Anna Boreczky, "Book Culture in Medieval Hungary", en The Art of Medieval Hungary, ed. por Xavier Barral i Altet et al. (Roma: Viella, 2018), 287-288.
} 
religiosa que aparece en actitud orante a los pies de Helena de Veszprém.

En definitiva, los aspectos analizados permiten fechar el díptico-relicario en el último cuarto del siglo XIII, cronología que confirmaría la tipología mariana empleada, en la que la Virgen y el Niño entrecruzan sus miradas, mientras el Niño posa su mano derecha sobre el pecho de su Madre, cuyo cuerpo dibuja un claro contrapposto, que se repite en las figuras de santa Úrsula, santa Catalina de Alejandría y santo Domingo de Guzmán. Por lo tanto, la datación aquí propuesta coincide con la ya apuntada por María Jesús Herrero Sanz y se corresponde con los reinados de Alfonso X el Sabio (1252-1284), Sancho IV de Castilla (1284-1295) y Fernando IV de Castilla (1295-1312). Sin embargo, los mencionados monarcas no parecen tener un nexo claro con Hungría, lo que hace apuntar hacia Violante de Aragón, hija de Jaime I de Aragón y Violante de Hungría, y esposa de Alfonso X el Sabio, como posible donante de la pieza objeto de estudio al monasterio de las Huelgas de Burgos ${ }^{26}$.

VIOLANTE DE ARAGÓN, ¿DONANTE DEL DÍPTICO-RELICARIO?

La documentación conservada permite reconstruir las relaciones mantenidas por Violante de Aragón con distintos monasterios y conventos, pero esta, aparentemente, no resulta tan clara en el caso del monasterio de las Huelgas de Burgos. A pesar de ello, Rocío Sánchez Ameijeiras y Pablo Abella Villar han defendido la vinculación de esta reina castellana con el mencionado monasterio cisterciense. Sánchez Ameijeiras relaciona a Violante de Aragón con las empresas funerarias de $1279 \mathrm{y}$, muy especialmente, con la consagración de los cementerios llevada a cabo el 4 de septiembre de ese mismo año,

${ }^{26}$ L'Art au temps des rois maudits..., 60; Melissa R. Katz, "The Final Testament of Violante de Aragón (c.1236-1300/01): Agency and (dis)Empowerment of a Dowager Queen", en Queenship in the Mediterranean, ed. por Elena Woodacre (New York: Palgrave Macmillan, 2013), 52. “en primer lugar porque el programa parece derivado de la muerte del primogénito; en segundo, el hecho de que oficie la consagración un obispo aragonés, y por último, el que Jofré de Loaysa levante la capilla de San Juan a la que trasladó los restos de sus padres don Jofré y doña Jacometa que habían sido ayos de la reina Violante y del infante Fernando de la Cerda"27.

Algunos autores, como Henrik Karge y James D'Emilio han subrayado lo sorprendente que resulta la elección del prelado, punto sobre el cual Rocío Sánchez Ameijeiras ha aportado una pista interpretativa de especial relevancia. La mencionada autora recuerda que Fernando de la Cerda (12551275), primogénito de Alfonso $X \mathrm{y}$, por lo tanto, heredero al trono, falleció de manera inesperada en Ciudad Real en 1275, siendo enterrado, según se recoge en la Crónica de de los reyes de Castilla, "en la iglesia del monasterio de las Huelgas", en un sepulcro que habría sido labrado inmediatamente después de su muerte, que se conserva aún in situ, conformando un arco que separa el primer tramo de la colateral norte del coro $^{28}$.

Tras dicha repentina pérdida, Alfonso $X$, quien se encontraba en Beaucaire, regresó a Castilla y se dirigió a Burgos, donde convocó cortes en 1276 para decidir cuál habría de ser la línea sucesoria al trono castellano,

${ }^{27}$ Rocío Sánchez Ameijeiras, “Crisis, ¿qué crisis? Sobre la escultura castellana de la primera mitad del siglo XIV", en El Trecento en obres. Art de Catalunya i art d'Europa al segle XIV, ed. por Rosa Alcoy i Pedrós (Barcelona: Edicions de la Universitat de Barcelona, 2009), 259-260, nota 63; Abella Villar, "Patronazgo regio castellano...", vol. I, 168 y 170 .

${ }^{28}$ Henrik Karge, “Die königliche Zisterzienserinnen abtei Las Huelgas de Burgos und die Aufände der gotischen Architektur in Spanien", en Actas del Coloquio de la Carl Justi-Vereinigung y del Seminario de Historia del Arte de la Universidad de Gotinga. Gotinga, del 4 al 6 de febrero de 1994, ed. por Christian Freigang (Madrid-Frankfurt am Main, 1999), 27. Cit. en James D'Emilio, “The royal convent of Las Huelgas: dynastic politics, religious reform and artistic change in medieval Castile", en Cistercian nuns and their world, ed. por Meredith P. Lillich (Kalamazoo: Cistercian Publications, 2005), 213-214; Sánchez Ameijeiras, “Crisis, ¿qué crisis? ...”, 260 y 265. 
si la de los hijos del primogénito, los infantes de la Cerda, o la del infante Sancho. Los hijos de Fernando de la Cerda obtuvieron el apoyo de Juan Núñez I de Lara y su hermano Nuño González de Lara, mientras que el infante Sancho contaba con el respaldo del infante Fadrique, hermano de Alfonso X, de Lope Díaz III de Haro, señor de Vizcaya, y de Simón Ruiz, señor de Cameros ${ }^{29}$.

A los mencionados apoyos con los que contaban los infantes de la Cerda, hay que añadir el de su abuela, la reina Violante de Aragón, quien, a consecuencia de la decisión tomada en las cortes de Segovia en 1278, por las cuales se nombró único heredero del trono del reino de Castilla y León al infante Sancho, abandonó Castilla, probablemente en junio de ese mismo año, y se dirigió a las tierras aragonesas de su hermano Pedro III, acompañada de su nuera, Blanca de Francia, y de sus nietos, Alfonso y Fernando ${ }^{30}$.

Sabemos que la reina regresó a Castilla en julio de 1279, por deseo de su hijo, Sancho IV. Según el testimonio de José Moreno Curiel, los cementerios se consagraron ese mismo año, "el 5 de Septiembre fueron dedicados el altar de la Santa Cruz, en el coro de las Monjas y el altar de todos los santos; $\mathrm{y}$ entonces fue dedicado el cementerio del noble rey Alfonso, fundador del monasterio, el cementerio de otros reyes, el cementerio de las infantas, y el capítulo", noticia que el mencionado autor habría visto anotada en el Calendario-Martirologio y Regla de San Benito ${ }^{31}$.

El acta que recoge la citada consagración de altares y cementerios señala al obispo de la diócesis de Segorbe-Albarracín,

${ }^{29}$ Abella Villar, "Patronazgo regio castellano...", vol. I, 171.

${ }^{30}$ Abella Villar, "Patronazgo regio castellano...", vol. I, 174.

${ }^{31}$ José Moreno Curiel, Jardín de Flores de Gracia, escuela de la mejor doctrina. Vida y virtudes de la prodigiosa y venerable Doña Antonia Jacinta de Navarra y de la Cueva, abadesa del Ilustrísimo Real Monasterio de las Huelgas (Burgos: Imprenta de Athanasio Figueroa, 1736), Introducción, sin paginar; Sánchez Ameijeiras, "Crisis, ¿qué crisis? ...", 259.
Miguel Sánchez (1278-1288), oficiante de la misma, por mandato de la señora monástica Berenguela, hermana del rey Alfonso X, quien desempeñó un papel fundamental en la conservación de la memoria familiar, en torno al panteón real del monasterio. El 2 de septiembre de dicho año fueron consagrados los altares dedicados a la Virgen María, san Nicolás, san Miguel, santo Tomás de Canterbury, Santiago el Mayor y santa Catalina de Alejandría. Al día siguiente se consagró el altar de san Bernardo y, el 4 de septiembre, los altares de la Santa Cruz y de Todos los Santos. Meses más tarde, el 15 de noviembre de 1279 se consagró un último altar, ubicado en la capilla adyacente de San Juan (in capella clericorum) $)^{32}$.

A pesar de que se han elaborado distintas propuestas de ubicación para los mencionados altares, como ha señalado Pablo Abella Villar, la documentación conservada tan solo indica la localización de uno, el altare Sanctae Crucis, que se encontraba in choro monialium. De acuerdo con Eduardo Carrero Santamaría, los coros de los monasterios cistercienses femeninos habrían contado con altares propios, probablemente ligados a los usos litúrgicos de cada comunidad, como pudo haber sido el caso del altar de la Santa $\mathrm{Cruz}^{33}$. Según Raquel Alonso Álvarez, este altar "es probablemente el adosado a la reja que separa el coro de monjas del transepto". El documento de 1279 se conoce a través de un traslado realizado en 1736 por Moreno Curiel, lo que ha llevado a Henrik Karge y James D'Emilio a cuestionar la autenticidad del mismo. Por el contrario, Raquel Alonso, Rocío Sánchez Ameijeiras y Olga Pérez Monzón han apoyado su veracidad, al no

32 Abella Villar, "Patronazgo regio castellano...", vol. I, 68; Carlos M. Reglero de la Fuente, "Las 'señoras' de las Huelgas de Burgos: infantas, monjas y encomenderas", e-Spania. Revue interdisciplinaire d'études hispaniques médiévales et modernes (2016), §28. https://doi. org/10.4000/e-spania.25542

${ }^{33}$ Eduardo Carrero Santamaría, "Epigrafía y liturgia entre el locutorio y el pasaje a la enfermería de la abadía de Santa María la Real de las Huelgas, en Burgos", Territorio, Sociedad y Poder, no 9 (2014), 178. 
comprender el interés que podría tener el copista para alterar la información contenida en el mencionado documento, opinión a la que me sumo ${ }^{34}$.

Como ha señalado Olga Pérez Monzón, muchas de las reliquias contenidas en el díptico objeto de estudio tienen un claro carácter cristológico. De hecho, sobre la representación de la Virgen con el Niño, y en eje con esta, se atesoraba en origen una reliquia de la Cruz, lo que hace pensar en la posibilidad de que esta pieza fuese donada, pocos años después de haber sido elaborada, al monasterio de las Huelgas y destinada al altar de la Santa Cruz. Ello explicaría que, siglos más tarde, el díptico-relicario se conservase en el armario-relicario del coro de las monjas ${ }^{35}$.

A pesar de la dificultad, motivada por la ausencia de documentación, de determinar cómo llegó el díptico-relicario al monasterio burgalés, según mi hipótesis, la encargada de donar la mencionada pieza a la comunidad de religiosas cistercienses pudo haber sido la reina Violante de Aragón. Esta habría recibido como regalo el díptico-relicario, procedente de Hungría, por sus directos vínculos familiares con la dinastía Arpad. La devoción de Violante de Aragón por las órdenes mendicantes queda demostrada a través de su labor de patronazgo. A lo largo de su vida favoreció a diversos conventos de

${ }^{34}$ Rocío Sánchez Ameijeiras, "La memoria de un rey victorioso: los sepulcros de Alfonso VIII y la fiesta del triunfo de la Santa Cruz", en Arte funerario y cultura sepulcral en España y Portugal, ed. por Barbara Borngässer, Henrik Karge y Bruno Klein (Madrid: Vervuert, Iberoamericana, 2006), 294; Raquel Alonso Álvarez, "La memoria de Alfonso VIII de Castilla en las Huelgas de Burgos: arquitectura y liturgia funeraria", en 1212, un año, un reinado, un tiempo de despegue. XXIII Semana de Estudios Medievales, ed. por Esther López Ojeda (Logroño: Instituto de Estudios Riojanos, 2013), 368; Pablo Abella Villar, "Espacio áulico y clausura de féminas en el Monasterio de Santa María la Real de Las Huelgas de Burgos", en Mujeres en silencio: el monacato femenino en la España Medieval, coord. por José Ángel García de Cortázar y Ramón Teja (Aguilar de Campoo: Fundación Santa María la Real del Patrimonio Histórico, 2017), 204-205.

\footnotetext{
${ }^{35}$ Pérez Monzón, “'Bien contar [supieron]'...", 132.
}

clarisas -Santa Clara de Murcia, Santa Clara de Santiago de Compostela, Santa Clara de Salamanca y Santa Clara de Allariz-, franciscanos -San Francisco de Valladolid- y dominicos -San Pablo de Valladolid- ${ }^{36}$. A ello habría que sumar el hecho de que en húngaro Helena es una variante del nombre Yolanda, Jolenta o Iolant, lo que haría de Helena de Veszprém la "santa" húngara homónima de la reina castellana. De hecho, Iolante es la variante de su nombre empleado por Violante de Aragón en la firma de documentos ${ }^{37}$.

Los relicarios ligados a la Corona habrían tenido su origen en encargos realizados a plateros del entorno de la corte, aunque muchos de ellos habrían sido fruto también de adquisiciones de terceros o donaciones, como pudo haber sido el caso de la pieza que nos ocupa. En este sentido cabe señalar que la presencia de reliquias y relicarios en la corte castellano-leonesa está perfectamente documentada desde época alfonsí. En su testamento, Alfonso X hizo entrega a la catedral de Sevilla del tríptico-relicario conservado en la actualidad en la sede hispalense. Esta pieza, datada por Teresa Laguna en el tercer cuarto del siglo XIII, hacia 1274, sería ligeramente anterior al díptico-relicario de las Huelgas ${ }^{38}$.

Pertenecientes a la reina Violante de Aragón, se conservaban en el monasterio de Santa Clara de Allariz un portapaz de plata con un viril en medio, con un Lignum Crucis "y en todo lo demás hueco muchedumbre de diversas reliquias", un portapaz de plata sobredorada "que tiene de la faxa con que

\footnotetext{
${ }^{36}$ María Jesús Fuente Pérez, Violante de Aragón. Reina de Castilla (Madrid: Dykinson, 2017), 172-174.

37 Salcedo Mendoza, Historia y Arte..., 261; Antoni Llull Martí, "Noms d'alguns personatges de la historia de Mallorca d'etimologia dubtosa o no prou aclarida (Violant, Esclarmonda, Nunó, Carròs, Àrias, Assalt, Magnet, Meem, Mingot, Proet i Vecià", en XXII Jornada d'antroponímia i toponímia (Pollença, 2009), ed. por Ramòn Bassa i Martín i Francesca Latorre Sánchez (Palma de Mallorca: Universitat de les Illes Balears, 2010), 167-168.

${ }^{38}$ Teresa Laguna Paúl, "Tablas alfonsíes”, en Alfonso $X$ el Sabio, dir. por Isidro Bango Torviso (Murcia: Ayuntamiento de Murcia, 2009), 638-639.
} 
fue ceñido Christo Nuestro Redenptor y una estilla de la cuna y una piedra del sepulchro de nuestra Señora", una imagen de Santiago de plata con un viril en su escudo en el que se dispondría un Lignum Crucis, una cruz de plata hueca con un dedo atribuido a san Bartolomé, dos cruces de plata hueca con diferentes reliquias, "ytem mas ay otra infinidad de Reliquias de diversos sanctos y sanctas que la Reina traxo a esta casa" ${ }^{\prime 39}$.

De ser cierta mi hipótesis, Violante de Aragón pudo haber querido donar un objeto devocional tan personal como el díptico-relicario, entroncado con sus raíces húngaras, al monasterio en el que reposaban los restos de su denostado primogénito, entre 1295, fecha en la que redactó su codicilo, en el que no incluye ninguna donación al monasterio de las Huelgas, y 1300, año en el que la reina, con motivo del Jubileo, partió a Roma, falleciendo en el camino. Si bien la reina dejó estipulado en su testamento que, a su muerte, las dueñas de su convento de Santa Clara de Allariz recibiesen toda su capilla, Violante de Aragón pudo haber hecho entrega, en vida, de la pieza objeto de estudio a la comunidad de las Huelgas, encargada de velar por los restos del fallecido infante. De hecho, resulta complicado creer que la reina no mantuviese relación alguna con las religiosas del convento en el que se encontraba el sepulcro de Fernando de la Cerda. Como ha apuntado Rocío Sánchez Ameijeiras, el hecho de que se consagrase un cementerio para aliorum regum, es decir, para otros reyes, cuando únicamente descansaba allí Enrique I (†1217), "podría querer indicar la condición regia del heredero Fernando de la Cerda", lo que confirmaría, una vez más, la intervención de la reina ${ }^{40}$.

${ }^{39}$ Patrocinio García Barriuso, "Documentación sobre la fundación, privilegios y derechos históricos del monasterio de Santa Clara de Allariz", Liceo franciscano, no $127-129$ (1990), 81.

${ }^{40}$ Alfredo Cid Rumbao, Historia de Allariz. Villa y corte románica (León: Evergráficas, 1984), 60-71; Katz, “The Final Testament of Violante de Aragón...", 52 y 55; Sánchez Ameijerias, "Crisis, ¿qué crisis? ...", 260, nota 63.
En definitiva, esta interpretación del proyecto cementerial como un instrumento de exaltación de la condición del primogénito como legítimo heredero, y con ello, la de sus descendientes, sumada a la hipotética donación del díptico-relicario por parte de Violante de Aragón a la comunidad de religiosas, pondría de manifiesto la relación de la reina castellana con el monasterio cisterciense, la cual merecería ser revisada y reconsiderada en futuras investigaciones.

\section{BIBLIOGRAFÍA}

Abella Villar, Pablo. "Patronazgo regio castellano y vida monástica femenina: morfogénesis arquitectónica y organización funcional del monasterio cisterciense de Santa María La Real de Las Huelgas de Burgos (ca. 1187-1350)". Tesis doctoral. Universitat de Girona, 2015.

Abella Villar, Pablo. "Espacio áulico y clausura de féminas en el Monasterio de Santa María la Real de Las Huelgas de Burgos". En Mujeres en silencio: el monacato femenino en la España Medieval, coordinado por José Ángel García de Cortázar y Ramón Teja, 187-221. Aguilar de Campoo: Fundación Santa María la Real del Patrimonio Histórico, 2017.

Alonso Álvarez, Raquel. "La memoria de Alfonso VIII de Castilla en las Huelgas de Burgos: arquitectura y liturgia funeraria". En 1212, un año, un reinado, un tiempo de despegue. XXIII Semana de Estudios Medievales, coordinado por Esther López Ojeda, 349-376. Logroño: Instituto de Estudios Riojanos, 2013.

Avril, François. L'enluminure à l'époque gothique, 1200-1420. París: Bibliotheque de l'image, 1979.

Benedictis, Cristina de. Devozione e produzione artística in Umbria. Vetri dorati e graffiti del XIV e XV secolo. Florencia: Edifir-Edizioni Firenze, 2010.

Berend, Nora. At the Gate of Christendom. Jews, Muslims and 'Pagans' in Medieval Hungary, 
c. 1000-c. 1300. Cambridge: Cambridge University Press, 2001.

Bernis, Carmen. "La moda y las imágenes góticas de la Virgen. Claves para su fechación". Archivo Español de Arte, XLIII, n⿳o 170 (1970), 193-218.

Boreczky, Anna. "Book Culture in Medieval Hungary". En The Art of Medieval Hungary, editado por Xavier Barral i Altet, Pál Lővei, Vinni Lucherini e Imre Takács, 283-303. Roma: Viella, 2018.

Carrero Santamaría, Eduardo. “Observaciones sobre la topografía sacra y cementerial de Santa María la Real de Las Huelgas, en Burgos, y su materialización arquitectónica". En La clausura femenina en España, coordinado por Francisco Javier Campos y Fernández de Sevilla, vol. 2, 695-715. San Lorenzo de El Escorial: Real Centro Universitario Escorial-María Cristina, 2004.

Carrero Santamaría, Eduardo. “Epigrafía y liturgia entre el locutorio y el pasaje a la enfermería de la abadía de Santa María la Real de las Huelgas, en Burgos". Territorio, Sociedad y Poder, no 9 (2014), 117-132.

Cid Rumbao, Alfredo. Historia de Allariz. Villa y corte románica. León: Evergráficas, 1984.

D’Emilio, James. "The royal convent of Las Huelgas: dynastic politics, religious reform and artistic change in medieval Castile". En Cistercian nuns and their world, editado por Meredith P. Lillich, 191-282. Kalamazoo: Cistercian Publications, 2005.

Deák, Viktória Hedvig. "Beguines in Hungary? The Case of St Margareta of Hungary (1242-71): A Mystic Without a Voice". En Mulieres religiosae: Shaping Spiritual Authority in the Medieval and Early Modern Periods, editado por Veerle Fraeters e Imke de Gier, 87-108. Turnhout: Brepols, 2014.

Falvay, Dávid. "Memory and Hagiography: The Formation of the Memory of Three
Thirteenth-Century Female Saints". En The Making of Memory in the Middle Ages, editado por Lucie Doležalová, 347-364. Leiden-Boston: Brill, 2010.

Fawtier, Robert. "La vie de la Bienheureuse Hélène de Hongrie". Mélanges d'archéologie et d'histoire, T. 33 (1913), 2-23.

Ferreiro Alemparte, Jaime. La leyenda de las once mil vírgenes. Sus reliquias, culto e iconografía. Murcia: Universidad de Murcia, 1991.

Fuente Pérez, María Jesús. Violante de Aragón. Reina de Castilla. Madrid: Dykinson, 2017.

García Barriuso, Patrocinio. "Documentación sobre la fundación, privilegios y derechos históricos del monasterio de Santa Clara de Allariz". Liceo franciscano, nº 127129 (1990), 11-107.

García Morilla, Alejandro. "Las inscripciones medievales de la provincia de Burgos: siglos VIII-XIII". Tesis doctoral. Universidad Complutense de Madrid, 2013.

Karge, Henrik. “Die königliche Zisterzienserinnen abtei Las Huelgas de Burgos und die Aufände der gotischen Architektur in Spanien". En Actas del Coloquio de la Carl Justi-Vereinigung y del Seminario de Historia del Arte de la Universidad de Gotinga. Gotinga, del 4 al 6 de febrero de 1994, editado por Christian Freigang, 13-40. Madrid-Frankfurt am Main, 1999.

Katz, Melissa R. “The Final Testament of Violante de Aragón (c.1236-1300/01): Agency and (dis)Empowerment of a Dowager Queen". En Queenship in the Mediterranean, editado por Elena Woodacre, 51-71. Nueva York: Palgrave Macmillan, 2013.

Klaniczay, Gábor. Holy Rulers and Blessed Princesses: Dynastic Cults in Medieval Central Europe. Cambridge: Cambridge University Press, 2002.

Klaniczay, Gábor. "Le stigmata di santa Margherita d'Ungheria: immagini e testi". Iconographica. Rivista di iconografía medievale e moderna", I (2002), 16-31. 
Klaniczay, Gábor. "On the Stigmatization of Saint Margaret of Hungary". En Medieval Christianity in Practice, editado por Miri Rubin, 274-282. Princeton: Princeton University Press, 2009.

Klaniczay, Gábor. "Pouvoir et idéologie dans l'hagiographie des saintes reines et princesses". En Hagiographie, idéologie et politique au Moyen Âge en Occident, editado por Edina Bozóky, 423-446. Turnhout: Brepols, 2012.

Klaniczay, Gábor. "Efforts at the Canonization of Margaret of Hungary in the Angevin Period". Hungarian Historical Review, no 2 (2013), 313-340.

Klaniczay, Gábor. "Sacred Sites in Medieval Buda". En Medieval Buda in Context, editado por Balázs Nagy, Martyn Rady, Katalin Szende y András Vadas, 229-254. Leiden-Boston: Brill, 2016.

Klaniczay, Gábor. "Saint Margaret: Royal and Female Sanctity". En Legenda Vetus, Acta Processus Canonizationis et Miracula Sanctae Margaritae de Hungria, editado por Ildikó Csepregi, Gábor Klaniczay y Bence Péterfi, 3-30. Budapest-Nueva York: Central European University Press, 2018.

Klaniczay, Gábor. "Estasi e stigmatizzazione: il miracolo vissuto e presentato". En Miracolo! Emozione, spettacolo e potere nella sotira dei secoli XIII-XVII, editado por Laura Andreani y Agostino Paravicini Bagliani, 157-172. Florencia: SISMEL, Edizioni del Galuzzo, 2019.

L'art au temps des rois maudits: Philippe le Bel et ses fils (1285-1328). París: Réunion des Musées Nationaux, 1998.

Laguna Paúl, Teresa. “Tablas alfonsíes”. En Alfonso $X$ el Sabio, dirigido por Isidro Bango Torviso, 638-639. Murcia: Ayuntamiento de Murcia, 2009.

Léonas, Alexis. Les Petites Fleurs de sainte Marguerite de Hongrie. París: Les Éditions du Cerf, 2013.
Llull Martí, Antoni. “Noms d'alguns personatges de la historia de Mallorca d'etimologia dubtosa o no prou aclarida (Violant, Esclarmonda, Nunó, Carròs, Àrias, Assalt, Magnet, Meem, Mingot, Proet i Vecià". En XXII Jornada d'antroponímia $i$ toponímia (Pollença, 2009), editado por Ramòn Bassa i Martín i Francesca Latorre Sánchez, 167-173. Palma de Mallorca: Universitat de les Illes Balears, 2010.

Millar, Eric G. The Parisian miniaturist Honoré. Londres: Faber and Faber, 1959.

Moreno Curiel, José. Jardín de Flores de Gracia, escuela de la mejor doctrina. Vida y virtudes de la prodigiosa y venerable Doña Antonia Jacinta de Navarra y de la Cueva, abadesa del Ilustrísimo Real Monasterio de las Huelgas. Burgos: Imprenta de Athanasio Figueroa, 1736.

Muessig, Carolyn. “The Stigmatic Debate in Theology and Art in the Late Middle Ages". En The Authority of the Word. Reflecting on Image and Text in Northern Europe, 1400-1700, editado por Celeste Brusati, Karl A. E. Enenkel y Walter S. Melion, 481-504. Leiden: Brill, 2012.

Pérez Monzón, Olga. “'Bien contar [supieron] las gestas del buen rey'. Memoria visual de Alfonso VIII". En Alfonso VIII y Leonor de Inglaterra: confluencias artísticas en el entorno de 1200, editado por Marta Poza Yagüe y Diana Olivares Martínez, 109-147. Madrid: Ediciones Complutense, 2017.

Reglero de la Fuente, Carlos M. "Las 'señoras' de las Huelgas de Burgos: infantas, monjas y encomenderas". e-Spania. Revue interdisciplinaire d'études hispaniques médiévales et modernes (2016). https://doi. org/10.4000/e-spania.25542

Romhányi, Beatriz F. "The Monastic Topography of Medieval Buda". En Medieval Buda in Context, editado por Balázs Nagy, Martyn Rady, Katalin Szende y András Vadas, 204-228. Leiden-Boston: Brill, 2016. 
Salcedo Mendoza, José Enrique. Historia y Arte en la Hungría medieval. Granada: Port-Royal Ediciones, 2014.

Sánchez Ameijeiras, Rocío. "La memoria de un rey victorioso: los sepulcros de Alfonso VIII y la fiesta del triunfo de la Santa Cruz". En Arte funerario y cultura sepulcral en España y Portugal, editado por Barbara Borngässer, Henrik Karge y Bruno Klein, 289-315. Madrid: Vervuert, Iberoamericana, 2006.

Sánchez Ameijeiras, Rocío. “Crisis, ¿qué crisis? Sobre la escultura castellana de la primera mitad del siglo XIV". En El Trecento en obres. Art de Catalunya $i$ art d'Europa al segle XIV, editado por Rosa Alcoy i Pedrós, 243-272. Barcelona: Edicions de la Universitat de Barcelona, 2009.
Sandler, Lucy F. Gothic Manuscripts, 12851385. Londres: Harvey Miller, 1986.

Tüskés, Anna. "The Cult of Ursula in Hungary: Legend, Altars and Reliquaries". En The Cult of St Ursula and the 11,000 Virgins, editado por Jane Cartwright, 187-204. Cardiff: University of Wales Press, 2016.

Végh, András. "Buda-Pest 1300 - Buda-Pest 1400. Two Topographical Snapshots". En Medieval Buda in Context, editado por Balázs Nagy, Martyn Rady, Katalin Szende y András Vadas, 169-203. Leiden-Boston: Brill, 2016.

Zupka, Dušan. Ritual and Symbolic Communication in Medieval Hungary under the Árpád Dynasty (100-1301). Leiden-Boston: Brill, 2016. 